Please do not remove this page

RMIT

UNIVERSITY

\title{
Acoustic properties of multilayer sound absorbers with a 3D printed micro-perforated panel
}

Liu, Zhengqing; Zhan, Jiaxing; Fard, Mohammad; Davy, John

https://researchrepository.rmit.edu.au/esploro/outputs/9921860806001341/filesAndLinks?institution=61RMIT_INST\&index=null

Liu, Z., Zhan, J., Fard, M., \& Davy, J. (2017). Acoustic properties of multilayer sound absorbers with a 3D printed micro-perforated panel. Applied Acoustics, 121, 25-32.

https://doi.org/10.1016/j.apacoust.2017.01.032

Document Version: Accepted Manuscript

Published Version: https://doi.org/10.1016/j.apacoust.2017.01.032

Repository homepage: https://researchrepository.rmit.edu.au

(c) 2017 Elsevier Ltd. All rights reserved

Downloaded On 2023/04/26 20:03:39 +1000

Please do not remove this page 
Thank you for downloading this document from the RMIT Research Repository.

The RMIT Research Repository is an open access database showcasing the research outputs of RMIT University researchers.

RMIT Research Repository: http://researchbank.rmit.edu.aul

\section{Citation:}

Liu, Z, Zhan, J, Fard, M and Davy, J 2017, 'Acoustic properties of multilayer sound absorbers with a 3D printed micro-perforated panel', Applied Acoustics, vol. 121, pp. 25-32.

See this record in the RMIT Research Repository at:

https://researchbank.rmit.edu.au/view/rmit:40078

Version: Accepted Manuscript

\section{Copyright Statement:}

(c) 2017. This manuscript version is made available under the CC-BY-NC-ND 4.0 license http://creativecommons.org/licenses/by-nc-nd/4.0/

Link to Published Version:

https://dx.doi.org/10.1016/j.apacoust.2017.01.032 


\title{
Acoustic properties of multilayer sound with a 3D printed micro- perforated panel
}

\author{
Zhengqing Liu ${ }^{a, \star}$, Jiaxing Zhan ${ }^{a}$, Mohammad Fard ${ }^{a}$, John Laurence Davy ${ }^{b}$ \\ ${ }^{\text {a }}$ School of Engineering, RMIT University, Bundoora 3083, Australia \\ ${ }^{\mathrm{b}}$ School of Science, RMIT University, Melbourne 3001, Australia
}

\begin{abstract}
This paper presents the sound absorption properties of a composite micro-perforated panel absorber (MPPA) whose front layer is produced by additive manufacturing. The MPPA layers are printed using a polymer material, where the different hole spacing is used to create different perforation ratios. The sound absorption coefficient is measured by using an impedance tube method, to investigate the effects of the perforation ratio and the depth of an airgap behind the MPPA. Also a porous material layer is attached behind the MPPA layer in order to produce a multi-layer sound absorber. The measurement results are compared to theoreticaltheoretical results. The comparisons show that the measured sound absorption coefficients are in good agreement with the theoretical model. The user of a porous sound absorbing material behind the microperforated panel broadens the frequency bandwith of the MPPA. The frequency of maximum sound absorption can be varied by altering the perforation ratio of the perforated panel and/or the depth of the airgap behind the panel.
\end{abstract}

Keywords: Micro-perforated panel; Porous sound absorbing material; 3D printing technology; Perforation ratio; Impedance tube test; Sound absorption coefficient

\section{Introduction}

The use of micro-perforated panel absorber (MPPA) is a feasible solution for enhancing the noise attenuation in various industry applications, for instance, ships, vehicles, aircrafts, and buildings. The MPPA is usually a thin panel with a large number of submillimeter diameter perforations in front of a rigidly backed air cavity, in order to provide the correct acoustical resistance and the low acoustic reactance in order to provide wide-band sound absorption properties. The geometric design of an MPPA to obtain the desired sound absorption coefficient is a relatively easy challenge, but it is difficult and costly to process such submillimeter size of perforations by using etching, jetting, micro-punch or laser technology. Some of the literature has presented feasible methods to produce MPPA's, such as using the infiltration method [1], the use of parallel perforated ceramic materials [2], and use of a microfiltering mesh [3]. Qian et al. [4] investigated sound absorption of MPPA with ultra-micro perforations using MEMS technology. High sound absorption in the low and medium frequency ranges was achieved. On the other hand, the actual drilling shapes were usually used instead of conventional circular holes. Slots or slits were punched to reduce the manufacturing process [[5]-[7]]. The acoustic behavior of a micro-slit panel was presented by Maa [8], and acoustic properties of a MPPA with arbitrary cross-sectional perforations were derived by Ning et al. [9]. The aim was to find an effective way to improve the sound absorption of the MPPA. Furthermore, the composite sound absorption structure was optimized for specific noise control applications. Wang et al. [10] proposed a bionic method to develop a new multi-layer sound absorption structure. The sound absorption for broadband and low-frequency noise was significantly improved. Kim et al. [[11],[12]] developed a composite helical

\footnotetext{
* Corresponding author. Tel:: +6143056 6611.

E-mail address: liu.zhengqing@rmit.edu.au (Z. Liu).
} 
shaped porous structure using carbon fiber to enhance the sound absorption. It was light and thin compared to conventional materials. Recently, an alternative method of using additive manufacturing to fabricate a high precision sound absorber was introduced and first studied by Liu et al. [13]. In this paper, the perforated layers were produced using 3D printing technology, and the sound absorption coefficients were measured and theoretically predicted.

The acoustic property of an MPPA largely depends upon the geometry structure, and its sound absorption is predictable. The propagation of the sound wave in a narrow tube was originally presented by Rayleigh [14], and it was simplified by Crandall [15] for holes which are short in comparison with the wavelength. However, the diameters of the perforations for conventional perforated panels are usually of the order of millimeters or centimeters, and they have little inherent acoustic resistance. This imperfection can be improved by reducing the hole diameter to a submillimeter size so that the narrow absorption peaks become much wider. Maa [[16], [17]] first proposed the use of a micro-perforated panel absorber, based on the theory developed by Rayleigh and Crandall [[14], [15]]. Simultaneously, he developed an approximate theory and a general theory to predict the acoustic properties of MPPA structures [[18], [19][19]]. Maa's early theoretical model [[16]-[18]] was applied, and particularly, was effective for an MPPA with circular holes and low perforation ratio. However, the interaction between neighboring holes strongly affects the acoustic properties of a MPPA. This is because the viscous boundary layer is significantly disturbed by the flow around the hole edges. Therefore, it is necessary to add the end corrections which including the additional resistance and mass reactance [19]. The properties of the acoustic impedance of an orifice were developed by Ingard and Labate [20], Ingard [21], Melling [22], and Stinson and Shaw [23]. An experimental investigation of the effects of hole interactions on the sound absorption of an MPPA was reported by Tayong et al. [24]. The acoustic resistance depends on the hole spacing, and the sound absorption decreased with a decrease of the hole spacing. The literature mentioned above has theoretically analyzed the acoustic properties of an MPPA, and the theoretical modifications were presented to improve the accuracy of the prediction.

An MPPA layer is usually mounted in front of a rigid wall, and the depth of the airgap between the MPPA and the rigid wall is varied to obtain the desired acoustical properties. The sound absorption of an MPPA by an airgap has been theoretically analyzed and experimentally validated [[25]-[27]]. Recently, Wang et al. [28] studied the sound absorption of an MPPA backed an irregularly shaped cavity. Yang et al. [29] developed a theoretical model to predict the absorption properties of MPPA for oblique incidence sound. Their study focused on tuning the effective sound absorption range of the MPPA and investigated the effect of the backing cavity shapes. Lee [30] investigated the absorption properties of an MPPA backed with a cavity with leaking edges. He has pointed out that the effect of the leakage would be substantial at low frequencies. However, the effective sound absorption bandwidth of a single MPPA was limited, and a large cavity depth was often not suitable for practical applications. This could be improved by using a multi-layer MPPA sound absorber [[31], [32]] to optimize the design and improve the sound absorption. Furthermore, an MPPA backed with a porous material maybe efficiently used to broaden the sound absorption [[13], [33], [34]]. It should be noted that the transfer matrix method [[35]-[38]] has been widely used to effective predict the sound absorption coefficient of the multi-layer acoustic absorber.

In this paper, the perforated layers were fabricated with different perforation ratios using additive manufacturing. A single MPPA layer backed by an airgap and an MPPA layer backed with a porous material and an airgap were studied. Their normal sound absorption coefficients were measured by using the impedance tube method. The acoustic mechanism of an MPPA layer backed with airgap wasmodelled using Maa's theory. The sound absorption an MPPA layer with a porous material and rigidly backed airgap behind the MPPA layer was calculated using the transfer matrix method. The acoustic properties of the theoretical model and the measured results are presented and discussed, to quantify effects of the perforation ratio of the MPPA layer, the depth of the airgap and the presence or absence of the porous material on the sound absorption coefficient.

\section{Theoretical background}


In this study, the multi-layer sound absorbers included an MPPA layer, a porous material, and an airgap. The sound absorption of an MPPA layer backed by airgap can be calculated using Maa's theory [18]. In order to predict the theoretical acoustic properties of a multi-layer sound absorber, the transfer matrix method was used. The transfer matrices of each layer were independently calculated and then connected to obtain the total surface impedance and sound absorption coefficient of the system. It should be noted that Maa's model [[16]-[19]] including end corrections was used to obtain the input acoustic impedance of the MPPA layer and the JCA (Johnson-Champoux-Allard) equivalent fluid model [[39]-[42]] was used to obtain the acoustic properties of the porous material.

\subsection{Acoustic impedance and sound absorption of the MPPA}

Fig. 1 shows the schematic diagram of an MPPA layer backed by an airgap in front of a rigid wall. In this case, the incident sound wave $P_{i}$ is normal to the surface of the MPPA layer. The relative acoustic impedance $z_{M}$ (normalized by dividing by $\rho_{0} c_{0}$ ) of an MPPA layer is calculated in the terms of the specific acoustic resistance $R$ and the specific acoustic reactance $M$. The theoretical formula proposed by Maa including the impedance of the MPPA layer and the end corrections can be obtained from the following equations [[18], [19]]:

$$
\begin{gathered}
z_{M}=(R+j M) / \rho_{0} c_{0}=r+j \omega m \\
r=\frac{32 \eta t}{p \rho_{0} c_{0} d^{2}}\left(\sqrt{1+\frac{x^{2}}{32}}+\frac{\sqrt{2}}{8} \frac{x d}{t}\right) \\
m=\frac{t}{p c_{0}}\left(1+\frac{1}{\sqrt{9+x^{2} / 2}}+0.85 \frac{d}{t}\right) \\
x=\frac{d}{2} \sqrt{\omega \rho_{0} / \eta}
\end{gathered}
$$

where $r$ is the normlized specific acoustic rsistance, $m$ is the normlized specific acoustic reactance, $\omega=2 \pi f$ is the angular frequency, $f$ is the frequency, $\rho_{0}$ is the ambient air density, $\eta$ is the coefficient of the kinematic viscosity of air, $c_{0}$ is speed of the sound, $t, d, p$ are the thickness, hole diameter and perforation ratio of an MPPA layer respectivelyand $x$ is the perforate constant. On the other hand, the normalized specific acoustic impedance of the rigidly backed airgap with depth of $D$ behind the MPPA layer is given by [19]:

$$
z_{D}=-j \cot \left(\omega D / c_{0}\right)
$$

The total normalized specific acoustic impedance $z_{\text {total }}$ and the normal sound absorption coefficient, $\alpha_{n}$ of the MPPA layer backed by airgap are then calculated by [[18], [32]]:

$$
\begin{gathered}
z_{\text {total }}=z_{M}+z_{D}=r+j\left(\omega m-\cot \left(\omega D / c_{0}\right)\right) \\
\alpha_{n}=\frac{4 \operatorname{Re}\left(z_{\text {total }}\right)}{\left[1+\operatorname{Re}\left(z_{\text {total }}\right)\right]^{2}+\left[\operatorname{Im}\left(z_{\text {total }}\right)\right]^{2}}=\frac{4 r}{(1+r)^{2}+\left(\omega m-\cot \left(\omega D / c_{0}\right)\right)^{2}}
\end{gathered}
$$

\subsection{Acoustic impedance of the porous material}

The propagation of a sound wave in a porous material which can be modelled as an equivalent fluid is fully described by the complex wave impedance and the complex wave number. Assume the porous material is motionless and that the frame of the porous material does not undergo displacement and deformation. Therefore, the air inside of a porous material can be replaced by an equivalent fluid [39]. The sound propagation in a porous material then can be calculated by a complex effective density, 
$\rho_{\text {eff }}$ and a complex bulk modulus, $K(\omega)$. The acoustic impedance $Z_{P}$ of the porous material may be obtained from the JCA equivalent fluid model, and it is given by [[39]-[42]]:

$$
\begin{gathered}
Z_{P}=\sqrt{\rho_{\text {eff }} K(\omega)} \\
\rho_{\text {eff }}=\alpha_{\infty} \rho_{o}\left(1+\frac{\sigma \phi}{j \omega \rho_{o} \alpha_{\infty}} \sqrt{1+j \omega \frac{4 \alpha_{\infty}^{2} \eta \rho_{o}}{\sigma^{2} \Lambda^{2} \phi^{2}}}\right) \\
K(\omega)=\gamma_{o} P_{o} /\left[\gamma_{o}-\left(\gamma_{o}-1\right)\left(1+\frac{8 \eta}{j \omega P_{r} \rho_{o} \Lambda^{\prime 2}} \sqrt{1+j \omega \frac{P_{r} \rho_{o} \Lambda^{\prime 2}}{16 \eta}}\right)^{-1}\right]
\end{gathered}
$$

where $\gamma_{0}$ is the specific heat ratio (adiabatic constant), $P_{0}$ is the static reference pressure, $P_{r}$ is the Prandtl number for the ambient fluid, $\alpha_{\infty}$ is the tortuosity, $\sigma$ is the flow resistivity, $\phi$ is the porosity and $\Lambda$ and $\Lambda^{\prime}$ are the viscous characteristic length and thermal characteristic length, respectively.

\subsection{Transfer matrix approach and the sound absorption coefficient}

The transfer matrix method is used to predict the theoretical acoustic properties of a multi-layer sound absorber including an MPPA layer, a porous material layer, and an airgap. A schematic of the multi-layer sound absorber is illustrated in Fig. 2. Applying the transfer matrix method [38], the total transfer matrix $T_{\text {total }}$ of a multi-layer sound absorber can be obtained by connecting the individual transfer matrices $T_{M P P A}, T_{\text {porous }}$ and $T_{\text {airgap }}$ in order [[35]-[38]]:

$$
\begin{gathered}
T_{M P P A}=\left[\begin{array}{cc}
1 & Z_{M} \\
0 & 1
\end{array}\right] \\
T_{\text {porous }}=\left[\begin{array}{cc}
\cos \left(k_{c} h\right) & j Z_{P} \sin \left(k_{c} h\right) \\
j \sin \left(k_{c} h\right) / Z_{P} & \cos \left(k_{c} h\right)
\end{array}\right] \\
T_{\text {airgap }}=\left[\begin{array}{cc}
\cos \left(k_{0} D\right) & j Z_{0} \sin \left(k_{0} D\right) \\
j \sin \left(k_{0} D\right) / Z_{0} & \cos \left(k_{0} D\right)
\end{array}\right] \\
T_{\text {total }}=\prod_{i=1}^{n} T_{i}=T_{M P P A} \cdot T_{\text {porous }} \cdot T_{\text {airgap }}=\left[\begin{array}{ll}
T_{11} & T_{12} \\
T_{21} & T_{22}
\end{array}\right]
\end{gathered}
$$

where $Z_{M}$ is the acoustic impedance of an MPPA layer, $Z_{0}$ is the acoustic impedance of air, which is given by $Z_{0}=\rho_{0} c_{0}, k_{0}$ is the wave number in the airgap in front of the rigid wall and it is given by $k_{0}=\omega / c . k_{c}$ is the complex wave number of the sound waves in the porous material. it can be calculated by $k_{c}=\omega \sqrt{\rho_{e f f} / K(\omega)}$, and $h$ is the thickness of the porous material. The surface acoustic impedance $Z_{s}$ and the sound absorption coefficient of a multi-layer sound absorber then can be calculated by [43]:

$$
\begin{gathered}
Z_{s}=T_{11} / T_{21} \\
\alpha_{n}=\frac{4 \operatorname{Re}\left(Z_{s} / \rho_{0} c_{0}\right)}{\left[1+\operatorname{Re}\left(Z_{s} / \rho_{0} c_{0}\right)\right]^{2}+\left[\operatorname{Im}\left(Z_{s} / \rho_{0} c_{0}\right)\right]^{2}}
\end{gathered}
$$

\section{Materials and measurement}

\subsection{Materials}


The polymer material named VisiJet-SL (Clear) purchased from 3D-Systems, Inc. was used in this study. It has the average composition of $60-75 \%$ of 4,4 '. Isopropylidenedicyclohexanol (HBPA), which was oligomeric reaction products with 1-chloro-2,3-epoxypropane, 15-25\% of 3-ethyl-3-hydroxymethyloxetane, and $1-5 \%$ of a mixture containing triarylsulfonium salts. The density (liquid) and density (solid) of VisiJet-SL (Clear) at $25^{\circ} \mathrm{C}$ were $1100 \mathrm{~kg} / \mathrm{m}^{3}$ and $1170 \mathrm{~kg} / \mathrm{m}^{3}$, respectively. Thus, the printed composite MPPA layers are lighter than a conventional MPPA made of metal. A $5 \mathrm{~mm}$ non-woven porous material was used. It was mainly made from recycled cotton fibers. This porous material has an average density of $96.6 \mathrm{~kg} / \mathrm{m}^{3}$, and it was punched to produce a $29 \mathrm{~mm}$ diameter test specimen to fit in the impedance tube. The acoustic properties of the selected porous material were: airflow resistivity $\sigma=$ $289000 \mathrm{~N} . \mathrm{s} / \mathrm{m}^{4}$, tortuosity $\alpha_{\infty}=1.46$, porosity $\phi=0.85$, viscous characteristic length $\Lambda=112 \mu \mathrm{m}$, and thermal characteristic length $\Lambda^{\prime}=224 \mu \mathrm{m}$. These acoustic material properties were measured by Liu et al. [[44]-[46]].

\subsection{MPPA Specimen preparation}

Fig. 3 shows the design of the MPPA structures and the prepared test specimens. Four polymer composite MPPA samples, namely MPPA1, MPPA2, MPPA3, and MPPA4, were fabricated by using a professional 3D printer (ProJet 7000) purchased from 3D-System Inc. The ProJet 7000 uses stereolithography (SLA) technology to print accurate and perfectly formed MPPA test specimens on a layer by layer approach using ultraviolet light. In this study, the test specimens were printed with a fine layer resolution of $0.0254 \mathrm{~mm}$; their accuracy was $0.0254-0.05 \mathrm{~mm}$ per $25.4 \mathrm{~mm}$ of part dimension. The four composite MPPA samples were designed with the same thickness $t=1 \mathrm{~mm}$, sample diameter 29 $\mathrm{mm}$, and hole diameter $d=0.6 \mathrm{~mm}$. These structural parameters were chosen in order to provide a reasonable amount of resistance and allow a suitable of perforation ratios to be used [[23], [47]]. It should be noted that they were printed with different hole spacings $b=5 \mathrm{~mm}$ for MPPA1, $4 \mathrm{~mm}$ for MPPA2, $3 \mathrm{~mm}$ for MPPA3 and $2 \mathrm{~mm}$ for MPPA4, respectively. Thus they provide a range of perforation ratios. The printed test specimens were rigorously measured and selected, in order to comply with the design requirement. The structural parameters of the MPPA test specimens are listed in Table 1.

\subsection{Sound absorption coefficient measurement}

The sound absorption coefficients were measured by using a two-microphone transfer function method, according to the ASTM E1050-12 standard [48]. The experiment was performed under the ambient laboratory temperature of $211{ }^{\circ} \mathrm{C}$ and relative humidity of $51 \%$. The velocity of sound was $343.9 \mathrm{~m} / \mathrm{s}$ and the density of air was $1.2 \mathrm{~kg} / \mathrm{m}^{3}$. Fig. 4 shows the measurement setup in the laboratory, where a Brüel \& Kjær impedance measurement tube Type 4206 was used to measure the sound absorption coefficient of the test specimens. The impedance tube inner diameter was $29 \mathrm{~mm}$, and the acoustic properties were measured in the frequency range from $500 \mathrm{~Hz}$ to $6400 \mathrm{~Hz}$ [45]. In this method, a loudspeaker generated a random sound signal at one end of the tube. The complex sound reflection coefficient $R$ of a test sample was calculated from the corrected acoustic transfer function $H_{12}$ between the two microphone positions [[49], [50]]. The normal incidence sound absorption coefficient $\alpha_{n}$ was then calculated by the equation $\alpha_{n}=1-|R|^{2}$. Furthermore, the sound absorption coefficients were measured with different depth airgaps behind the MPPA, and also with a porous material layer as mentioned above to form a multi-layer sound absorber.

\section{Results and discussion}

\subsection{Comparison of the results}

Fig. 5 demonstrates the comparison of the sound absorption coefficient graphs of the measurement and prediction for the sample MPPA1 backed by an airgap, and a multi-layer acoustic 
absorber (rigidly backed airgap with a porous material behind the MPPA1 layer). It can be seen that the sound absorption coefficient results obtained by the analytical method agree reasonably well with the measurement data. The predicted peak sound absorption coefficient values and their corresponding frequencies agree fairly well with the measurement results. The maximum sound absorption coefficient for the case of the MPPA1 layer backed by an airgap occurs at the resonant frequency of $3700 \mathrm{~Hz}$. The peak sound absorption coefficient for the multi-layer acoustic absorber occurs at the resonant frequency of $2500 \mathrm{~Hz}$. One can notice that the maximum sound absorption coefficient values were obtained when the imaginary part of the normalized acoustic impedance equals zero. Moreover, there are some fluctuation peak values visible at frequencies below $2000 \mathrm{~Hz}$ for the experiment data. Those peaks commonly correspond with fundamental modes of the MPPA layer itself and air resonances of the impedance tube. In short, Maa's model and the transfer matrix method are validated for the prediction of the acoustic sound absorption of the 3D printed MPPA samples.

\subsection{Perforation ratio on the effect of the sound absorption coefficient}

The effect of the perforation ratio on the sound absorption coefficient of the four MPPA layers, when backed by an airgap and combined with a porous material, is shown in Fig. 6 . In this case, the distance between the MPPA layer and the rigid wall is the same as the thickness of the porous material layer. It can be seen that increasing the perforation ratio of the MPPA layer yields a higher acoustic resonance frequency for the peak sound absorption coefficient, for both the case of an MPPA layer backed by an airgap and backed with a porous material. This is because an increase of the perforation ratio results in the decrease of the total acoustic mass of all the holes and thus increases the resonant frequency at which maximum the sound absorption coefficient occurs. Besides, it can be seen that the peak sound absorption coefficients and the corresponding frequencies had no obvious changes, for both the case of MPPA layer backed by the airgap and backed with a porous material layer. However, for the case of an MPPA layer backed by a porous material, the higher perforation ratio demonstrates wider broadband sound absorption ranges. At lower frequencies, a smaller perforation ratio of MPPA layer gives a better peak sound absorption coefficient whereas a higher perforation ratio can control the sound absorption at higher frequencies. To obtain the desired peak sound absorption coefficient frequency and a wider frequency range, it is necessary to adjust the perforation ratio of the MPPA layer or combine with an appropriate porous material layer.

\subsection{Effect of the airgap}

Fig. 7 shows the sound absorption coefficient of the MPPA layer for the case of different depth airgaps $(2 \mathrm{~mm}, 4 \mathrm{~mm}, 6 \mathrm{~mm}$ and $8 \mathrm{~mm})$ behind the test samples in the impedance tube. Here, all sound absorption coefficient graphs, regardless of perforation ratio, show a similar variation: the width of the peak sound absorption increases with increasing depth of the airgap, and this also shifts the maximum sound absorption coefficient to the low-frequency range. This is due to the holes, which are open at both ends, acting as an acoustic mass and the airgap acting as an acoustic spring which creates a mass-spring resonance. The peak sound absorption occurs when the stiffness of the air cavity cancels the mass of the holes. An increase in the depth of the airgap reduces the stiffness of the airgap and thus moves the absorption peak towards the lower frequencies, as well as broadening the bandwidth of the peak sound absorption coefficient. Moreover, the results reveal that for a small perforation ratio sample (MPPA $1, p=0.9 \%, b=5 \mathrm{~mm}$ ), the maximum sound absorption coefficient value progressively increases with an increase in the depth of the airgap. However, for large perforation ratio samples (MPPA3 and MPPA4), the maximum sound absorption coefficient progressively decreases with an increase in the depth of the airgap. It should be noted that the peak sound absorption coefficient for MPPA2 ( $p=1.59 \%, b=4 \mathrm{~mm})$ is the highest, and it remains constant with the change of the depth of the

airgap. Nevertheless, for a large perforation ratio sample (MPPA4, $p=5.9 \%, b=2 \mathrm{~mm}$ ), the sound absorption capabilities are not satisfactory. In order to design an MPPA layer to obtain the desired sound 
absorption capability, it is necessary to combine the influencing factors of thickness, perforation ratio and depth of the airgap behind the MPPA layer. It is also feasible to attach a porous material layer to broaden the sound absorption frequency bandwidth.

\subsection{Acoustic properties of a multi-layer sound absorber}

Fig. 8 shows the measured sound absorption coefficient results of the multi-layer sound absorber including an MPPA layer, a porous material layer and an airgap to a rigid wall. All acoustic property graphs show that the multi-layer sound absorber has wider bandwidth sound absorption. However, significant changes are not observed at high frequencies, although at low to mid frequencies, the expected effect is achieved. In this case, the MPPA layer provides the acoustic mass reactance which cancels the acoustic stiffness reactance of the layer of the porous material and the airgap in front of a rigid backing at the peak sound absorption coefficient frequency. The sound absorption capabilities become broader, and it covers a wider frequency range. This is due to the fact that the air resonance in the airgap and porous material layer is further damped by the porous material layer. Thus, an MPPA layer with an attached porous material layer in front of an airgap makes the MPPA absorber more wideband. Simultaneously, the depth of the airgap controls the resonant frequency of the peak sound absorption coefficient.

\section{Conclusions}

In this study, a new method to produce an MPPA layer has been successfully developed by using additive manufacturing. The sound absorption coefficient of a 3D printed MPPA layer backed by an airgap and also with an attached porous material was measured and theoretically predicted. The normal sound absorption coefficients were measured by using the impedance tube method. The prediction method was based on Maa's theory, and the sound absorption coefficient of the multi-layer sound absorber was calculated using the transfer matrix method. It has been shown that the measurement results agree fairly well with the theoretically model. The effects of perforation ratio and the depth of the airgap were presented. The results indicated that increasing the perforation ratio of the MPPA layer yields a higher acoustic resonance frequency for the peak sound absorption coefficient. The acoustic resonant frequency was found to depend on the depth of the airgap behind the MPPA layer. The acoustic resonant frequency of the corresponding peak value of sound absorption coefficient was reduced, with increasing airgap behind the test samples in the impedance tube. The significant improvement of the sound absorption coefficient at low to mid frequencies can be attributed to the porous material layer and the airgap. The multi-layer sound absorber gives wider broadband sound absorption. The results obtained in this paper provide a new approach for the fabrication of a composite sound absorber for noise control applications.

\section{Acknowledgments}

The authors would like to thank Excellerate Australia Ltd (Australia) and Futuris Automotive Group (Australia) for their financial support for this research. The authors are also thankful to Dr. Ratchaphon Ittianuwat, Mr. Andre Clemann, Mr. Paul Porter, Mr. Mark Overend, and Mr. Patrick Wilkins for their technical support. Zhengqing Liu is grateful to Mr. Peter Tkatchyk in preparing a series of experiments.

\section{References}

[1] Cobo P, Espinosa FM. Proposal of cheap microperforated panel absorbers manufactured by infiltration. Appl Acoust 2013;74:1069-75

[2] Yang D, Wang X, Zhu M. The impact of the neck material on the sound absorption performance of Helmholtz resonators. J Sound Vib 2014;333:6843-57. 
[3] Ruiz H, Cobo P, Dupont T, Martin B, Leclaire P. Acoustic properties of plates with unevenly distributed macroperforations backed by woven meshes. J Acoust Soc Am 2012;132:3138-47.

[4] Qian YJ, Kong DY, Liu SM, Sun SM, Zhao Z. Investigation on micro-perforated panel absorber with ultra-micro perforations. Appl Acoust 2013;74:931-5.

[5] Kristiansen UR, Vigran TE. On the design of resonant absorbers using a slotted plate. Appl Acoust 1994;43:39-48.

[6] Randeberg RT. Adjustable slitted panel absorber. Acta Acust United Ac 2002;88:507-12.

[7] Stinson M. The propagation of plane sound waves in narrow and wide circular tubes, and generalization to uniform tubes of arbitrary cross-sectional shape. J Acoust Soc Am 1991;89:550-8.

[8] Maa DY. Theory of microslit absorbers. Acta Acoust 2000;25:481-5.

[9] Ning JF, Ren SW, Zhao GP. Acoustic properties of micro-perforated panel absorber having arbitrary cross-sectional perforations. Appl Acoust 2016;111:135-42.

[10] Wang Y, Zhang C, Ren L, Ichchou M, Galland MA, Bareille O. Sound absorption of a new bionic multi-layer absorber. Compos Struct 2014;108:400-8.

[11] Kim BS, Cho SJ, Min DK, Park J. Sound absorption structure in helical shapes made using fibrous paper. Compos Struct 2015;134:90-4.

[12] Kim BS, Cho SJ, Min DK, Park J. Experimental study for improving sound absorption of a composite helical-shaped porous structure using carbon fiber. Compos Struct 2016;145:242-7.

[13] Liu Z, Zhan J, Fard M, Davy JL. Acoustic properties of a porous polycarbonate material produced by additive manufacturing. Mater Lett 2016;181:296-9.

[14] Rayleigh L. The theory of sound. London: MacMillan; 1929.

[15] Crandall IB. Theory of vibrating system and sound. New York: Van Norstrand; 1926.

[16] Maa DY. Theory and design of microperforated panel sound-absorbing construction. Sci Sin 1975;18:55-71.

[17] Maa DY. Microperforated panel wide-band absorber. Noise Cont Eng J 1987;29:77-84.

[18] Maa DY. General theory and design of microperforated-panel absorbers. Acta Acoust 1997;22:385-93.

[19] Maa DY. Potential of microperforated panel absorber. J Acoust Soc Am 1998;104:2861-6.

[20] Ingard U, Labate S. Acoustic circulation effects and the nonlinear impedance of orifices. J Acoust Soc Am 1950;22:211-8.

[21] Ingard U. On the theory and design of acoustic resonators. J Acoust Soc Am 1953;25:1037-61.

[22] Melling TH. The acoustic impedance of perforates at medium and high sound pressure levels. J Sound Vib 1973;125:165.

[23] Stinson MR, Shaw E. Acoustic impedance of small, circular orifices in thin plates. J Acoust Soc Am 1985;77:2039-42.

[24] Tayong R, Dupont T, Leclaire P. Experimental investigation of holes interaction effect on the sound absorption coefficient of micro-perforated panels under high and medium sound level. Appl Acoust 2011;72:777-84.

[25] Kang J, Fuchs HV. Predicting the absorption of open weave textiles and micro-perforated membranes backed by an air space. J Sound Vib 1999;220:905-20.

[26] Lee YY, Lee EWM, Ng CF. Sound absorption of a finite flexible micro-perforated panel backed by an air cavity. J Sound Vib 2005;287:227-43.

[27] Bravo T, Maury C, Pinhède C. Sound absorption and transmission through flexible micro-perforated panels backed by an air layer and a thin plate. J Acoust Soc Am 2012;131:3853-63.

[28] Wang C, Cheng L, Pan J, Yu G. Sound absorption of a micro-perforated panel backed by an irregular-shaped cavity. J Acoust Soc Am 2010;127:238-46.

[29] Yang C, Cheng L, Pan J. Absorption of oblique incidence sound by a finite micro-perforated panel absorber. J Acoust Soc Am 2013;133:201-9.

[30] Lee YY. The effect of leakage on the sound absorption of a nonlinear perforated panel backed by a cavity. Int $\mathrm{J}$ Mech Sci 2016;107:242-52.

[31] Mu RL, Toyoda M, Takahashi D. Sound insulation characteristics of multi-layer structures with a microperforated panel. Appl Acoust 2011;72:849-55.

[32] Min S, Nagamura K, Nakagawa N, Okamura M. Design of compact micro-perforated membrane absorbers for polycarbonate pane in automobile. Appl Acoust 2013;74:622-7.

[33] Mechel FP. Helmholtz resonators with added porous absorbers. Acta Acoust United Ac 1994;80:268-79.

[34] Sakagami K, Kobatake S, Kano K, Morimoto M, Yairi M. Sound absorption characteristics of a single microperforated panel absorber backed by a porous absorbent layer. Acoust Australia 2011;39:95-100.

[35] Song BH, Bolton JS. A transfer-matrix approach for estimating the characteristic impedance and wave numbers of limp and rigid porous materials. J Acoust Soc Am 1999;107:1131-52.

[36] Atalla N, Panneton R. Acoustic absorption of macro-perforated porous materials. J Sound Vib 2001;243:659-78.

[37] Lee DH, Kwon YP. Estimation of the absorption performance of multiple layer perforated panel system by transfer matrix method. J Sound Vib 2004;278:847-60.

[38] Verdière K, Panneton R, Elkoun S, Dupont T, Leclaire P. Transfer matrix method applied to the parallel assembly of sound absorbing materials. J Acoust Soc Am 2013;134:4648-58.

[39] Johnson DL, Koplik J, Dashen R. Theory of dynamic permeability and tortuosity in fluid-saturated porous-media. J Fluid Mech 1987;176:379-402.

[40] Champoux Y, Allard JF. Dynamic tortuosity and bulk modulus in air-saturated porous-media. J Appl Phys 1991;70:1975-9. 
[41] Allard JF, Champoux Y. New empirical equations for sound propagation in rigid frame fibrous materials. J Acoust Soc Am 1992;91:3346-53.

[42] Allard JF, Atalla N. Propagation of sound in porous media: Modelling sound absorbing material. Chichester: Wiley; 2009.

[43] Zhao X, Fan X. Enhance low frequency sound absorption of micro-perforated panel absorber by using mechanical impedance plates. Appl Acoust 2015;88:123-8.

[44] Liu Z, Fard M, Davy JL. The effects of porous materials on the noise inside a box cavity. In: The 22nd International Congress on Sound and Vibration (ICSV22), Florence, 12-16 July 2015. p. 1-8.

[45] Liu Z, Fard M, Jaza R. Development of an acoustic material database for vehicle interior trims. In: 18th Asia Pacific Automotive Engineering (APAC18), Melbourne, 10-12 March 2015. p. 1-7.

[46] Liu Z, Fard M, Davy JL. Acoustic properties of the porous material in a car cabin model. In: The 23rd International Congress on Sound and Vibration (ICSV23), Athens, 10-14 July 2016. p. 1-8.

[47] Mosko JD, Fletcher JL. Evaluation of the Gundefender earplug: temporary threshold shift and speech intelligibility. J Acoust Soc Am 1971;49:1732-3.

[48] ASTM E1050-12. Standard test method for impedance and absorption of acoustical materials using a tube, two microphones and a digital frequency analysis system. New York: American National Standards Institution; 2012.

[49] Chung JY, Blaser DA. Transfer function method of measuring in-duct acoustic properties. J Acoust Soc Am 1980;68:90713.

[50] Koruk H. An assessment on the performance of impedance tube method. Noise Contr Eng J 2014;62:264-74.

\section{Figure Captions}

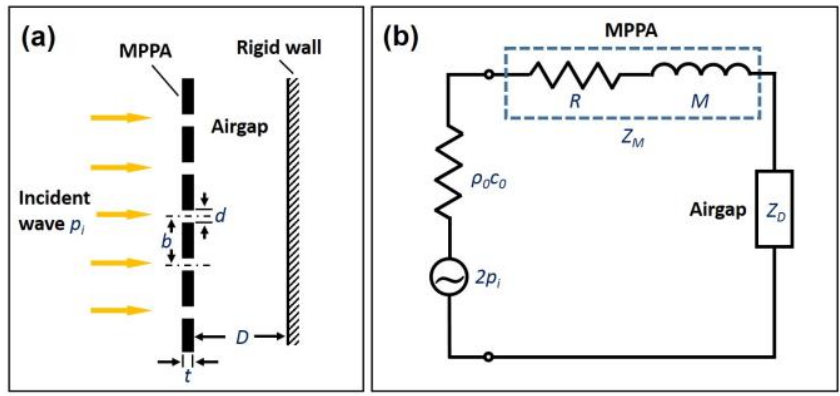

Fig. 1. (a) Schematic diagram of an MPPA layer backed by an airgap, and (b) its electro-acoustical equivalent circuit model.

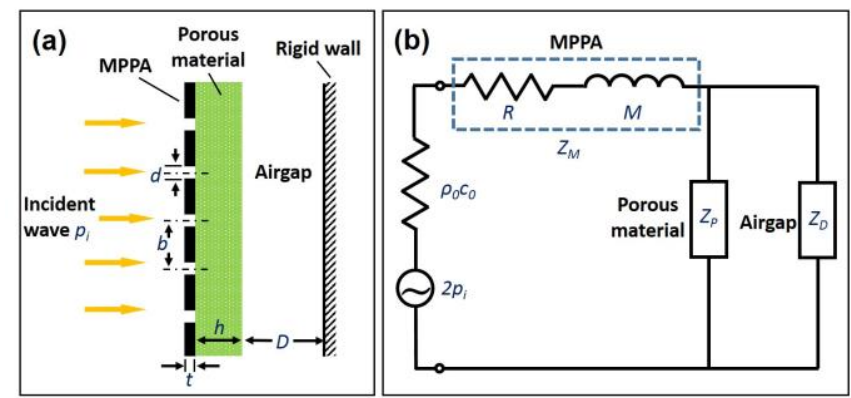

Fig. 2. (a) Schematic diagram of a composite MPPA layer backed by an airgap, and (b) it's electro-acoustical equivalent circuit model. 

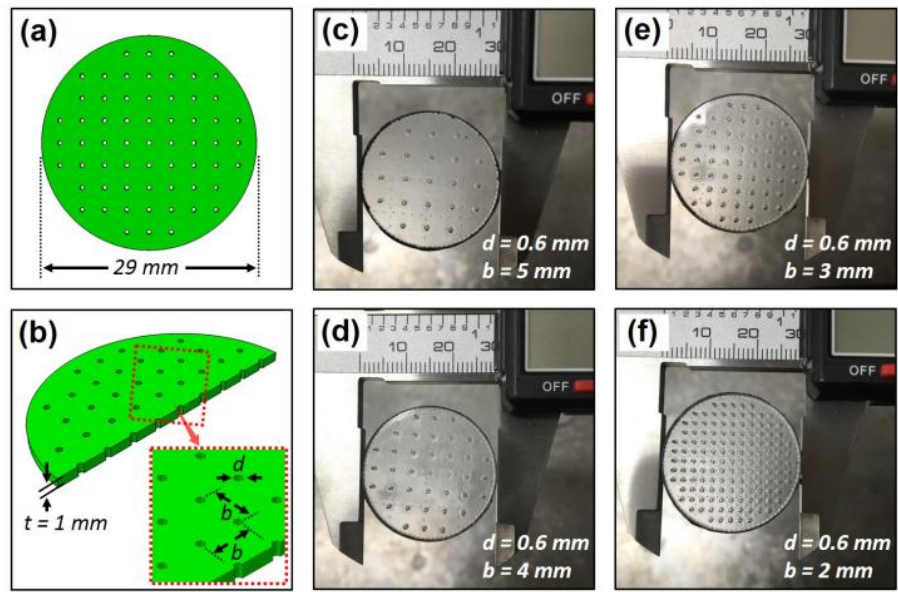

Fig. 3. 3D printed MPPA samples: (a) \& (b) geometry of the test samples, (c) MPPA1, $p=0.90 \%,(d)$ MPPA2, $p=1.59 \%$, (e) MPPA3, $p=2.63 \%$, and (f) MPPA4, $p=5.90 \%$.
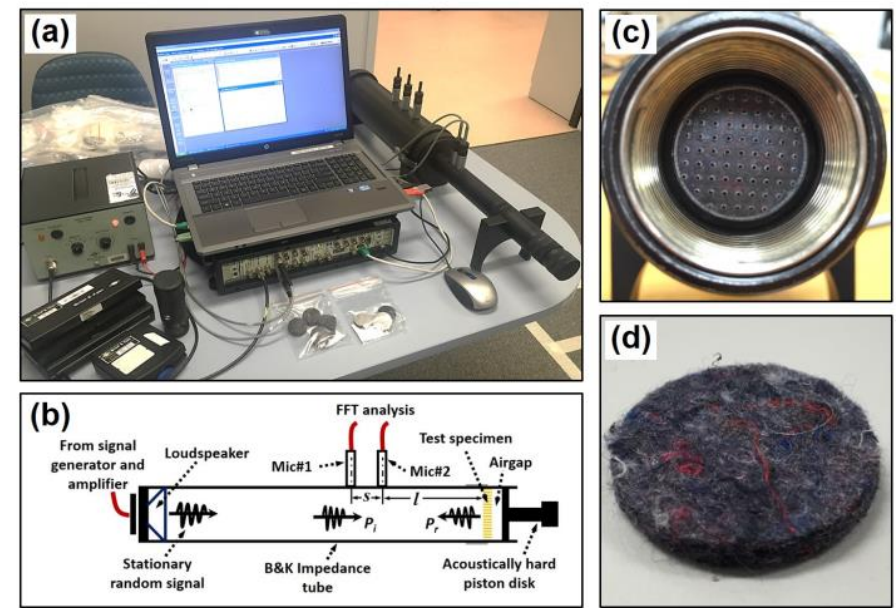

Fig. 4. (a) Sound absorption coefficient measurement setup in the laboratory, (b) schematic of impedance tube method, (c) test specimen mounted inside the impedance tube, and (d) porous material specimen.

(a)

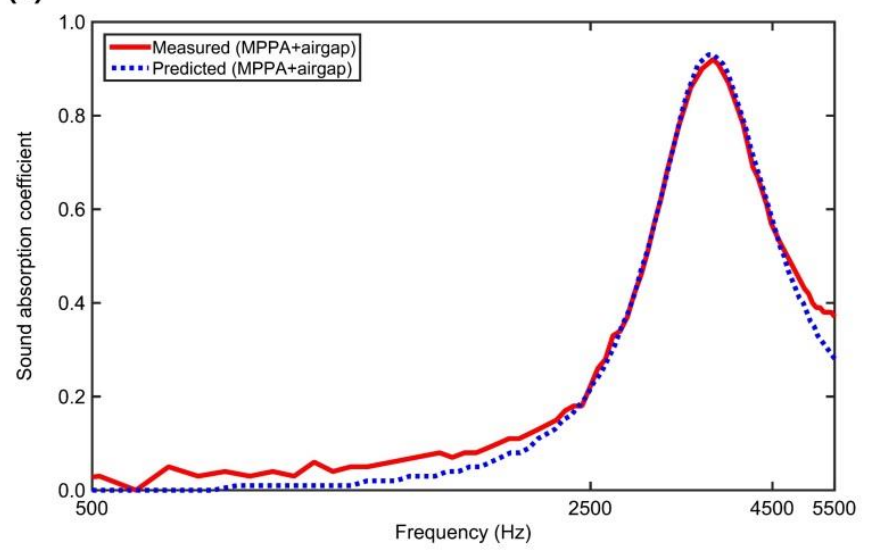

(b)

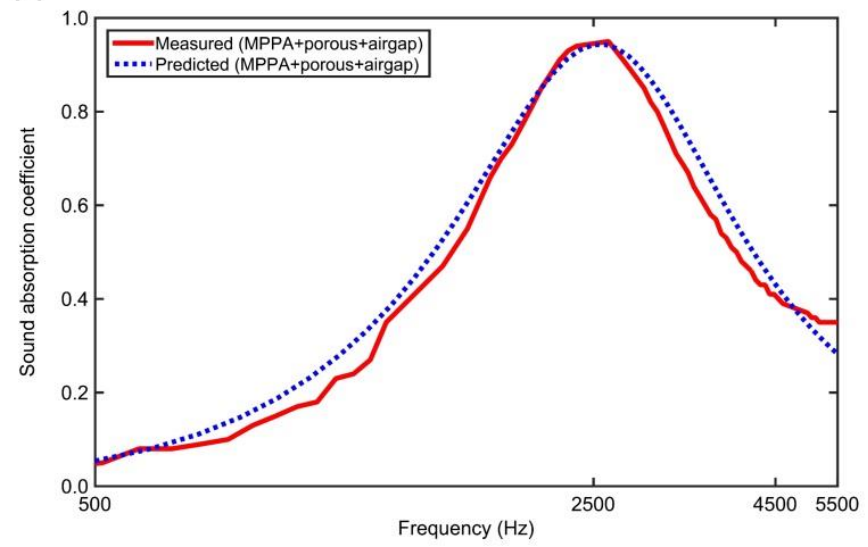

Fig. 5. Comparison of the measured and predicted sound absorption coefficients for (a) MPPA1 with a 2mm airgap, (b) MPPA1 backed by a porous material. 
(a)

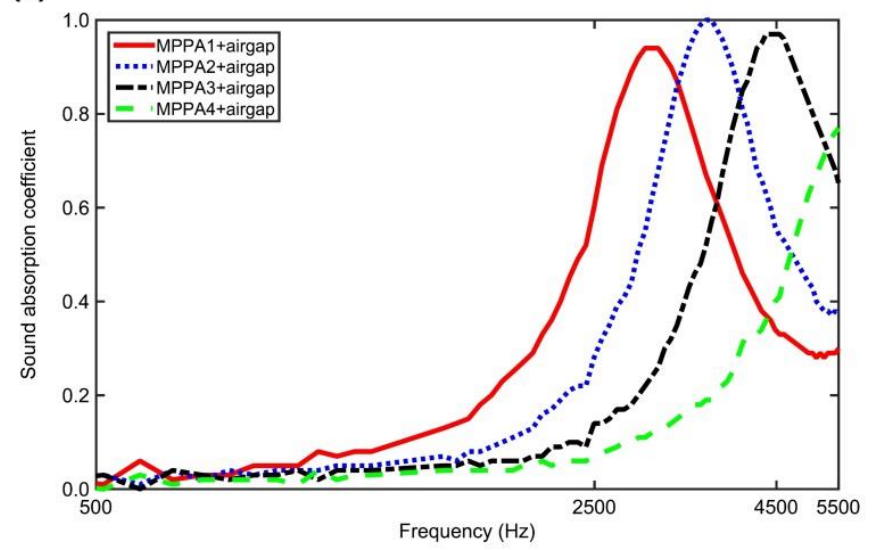

(b)

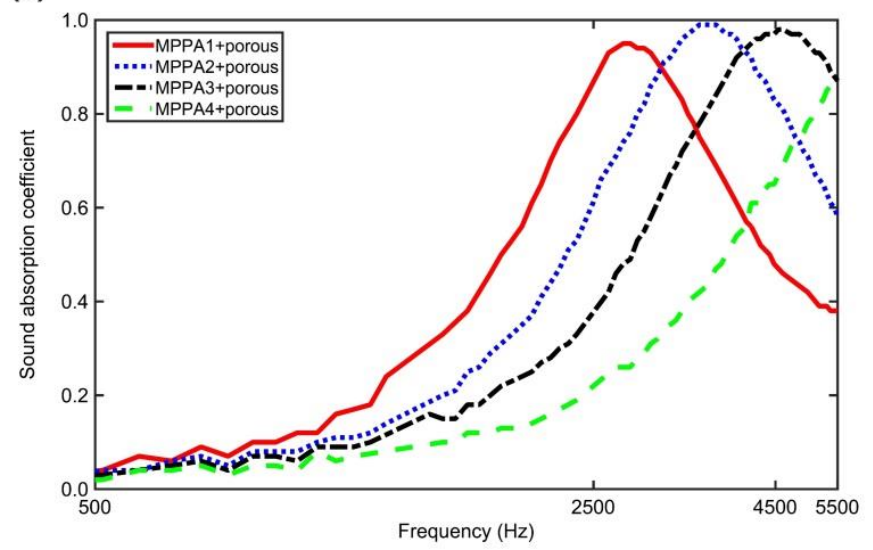

Fig. 6. Influence of perforation ratio on the sound absorption coefficient for MPPA layer backed by (a) $5 \mathrm{~mm}$ airgap, and (b) a 5 $\mathrm{mm}$ porous material.

(a)

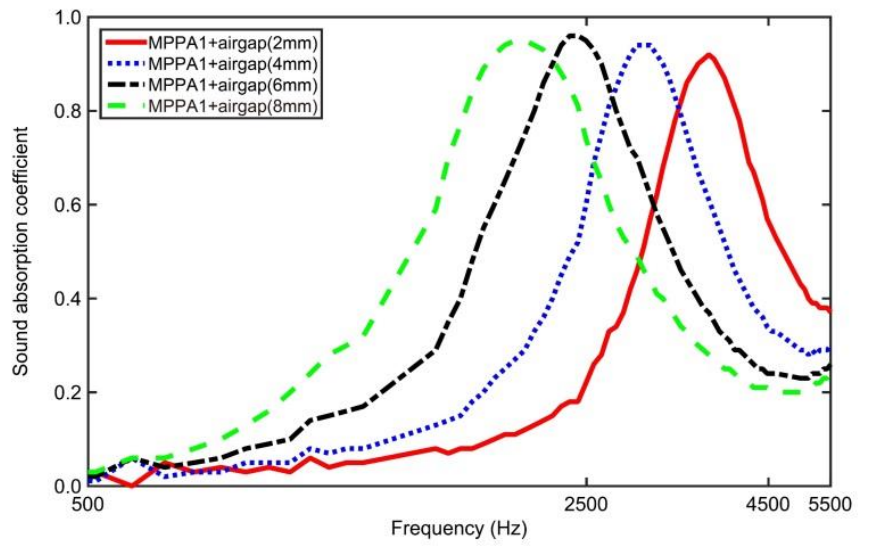

(c)

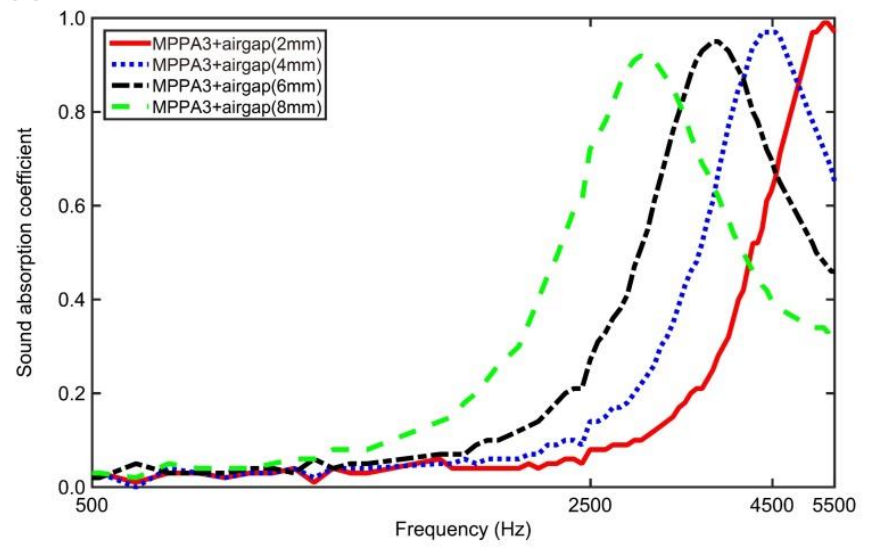

(b)

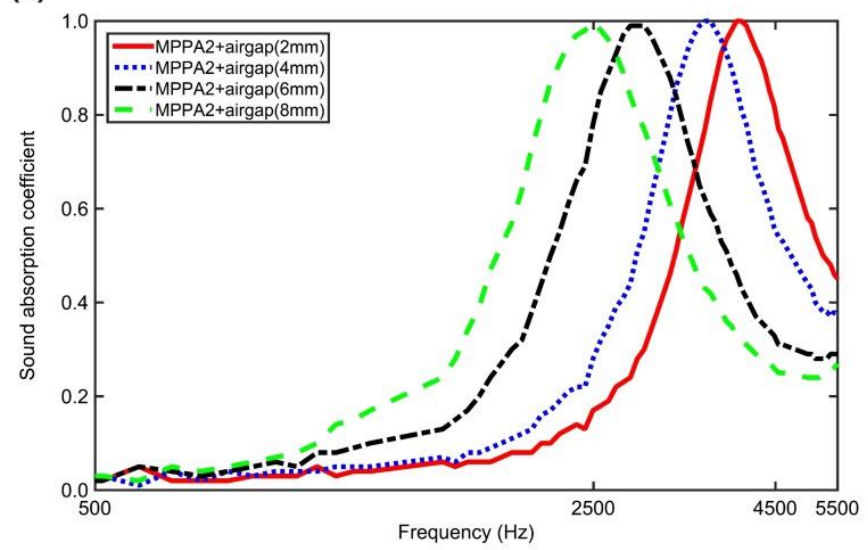

(d)

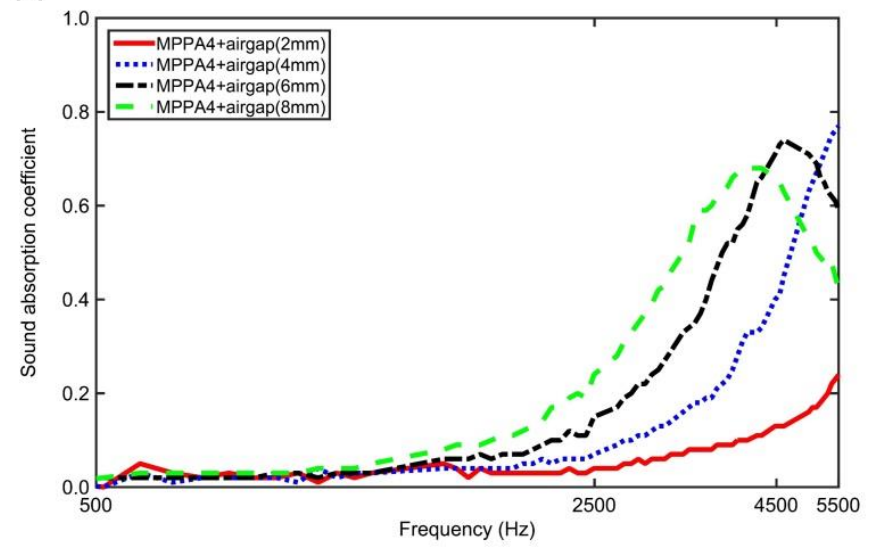

Fig. 7. The measured sound absorption coefficient of (a) MPPA1, (b) MPPA2, (c) MPPA3 and (d) MPPA4 with different airgap depths. 
(a)

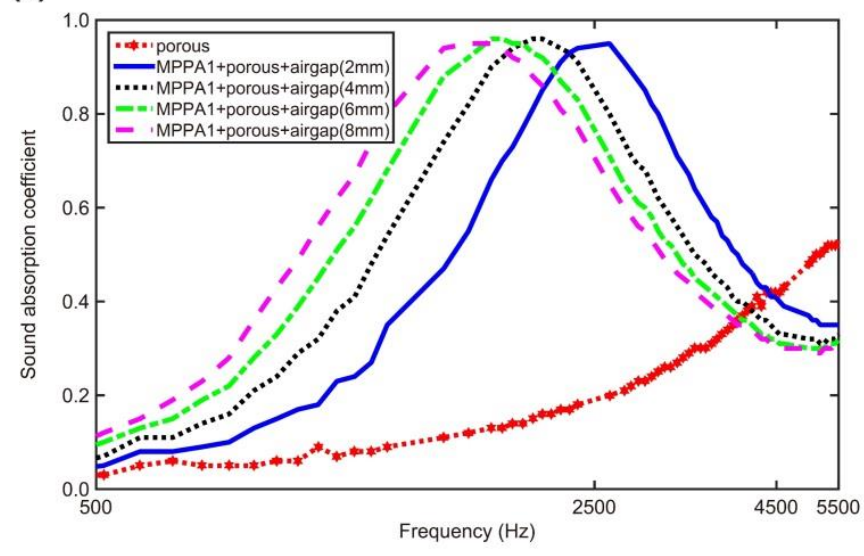

(c)

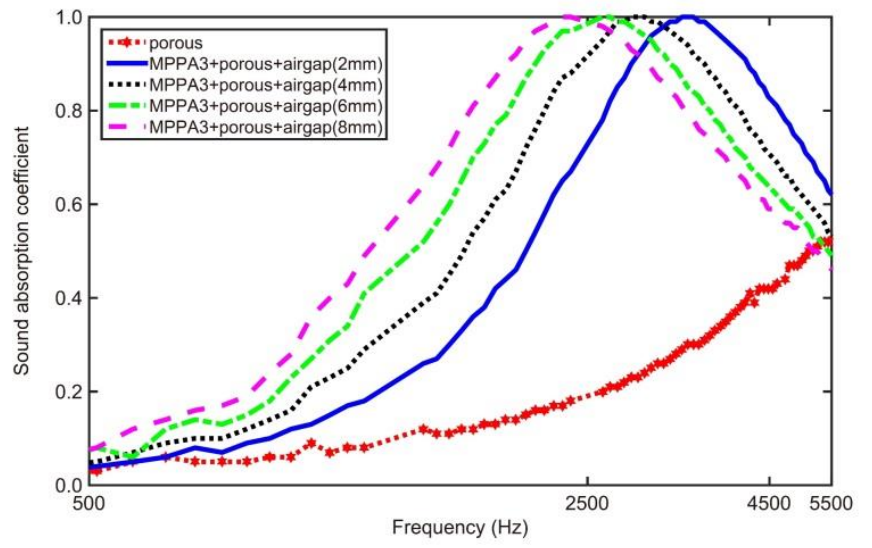

(b)

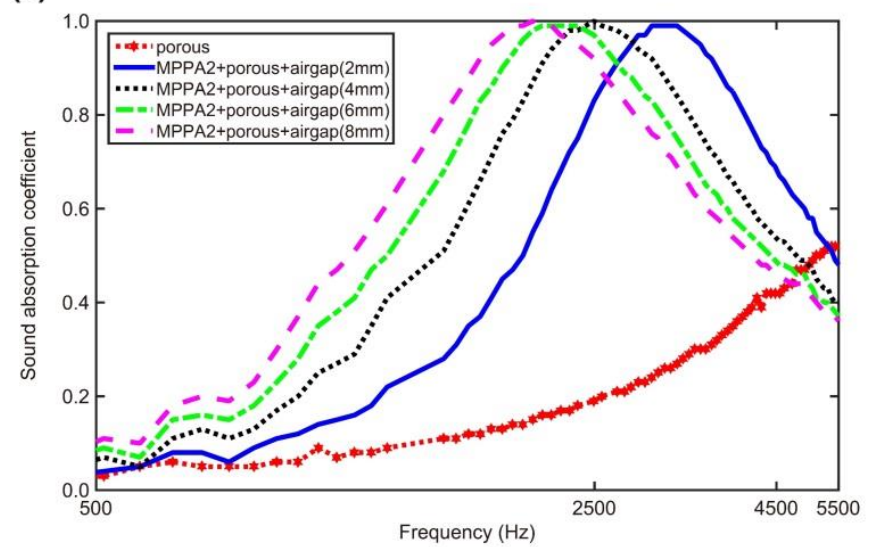

(d)

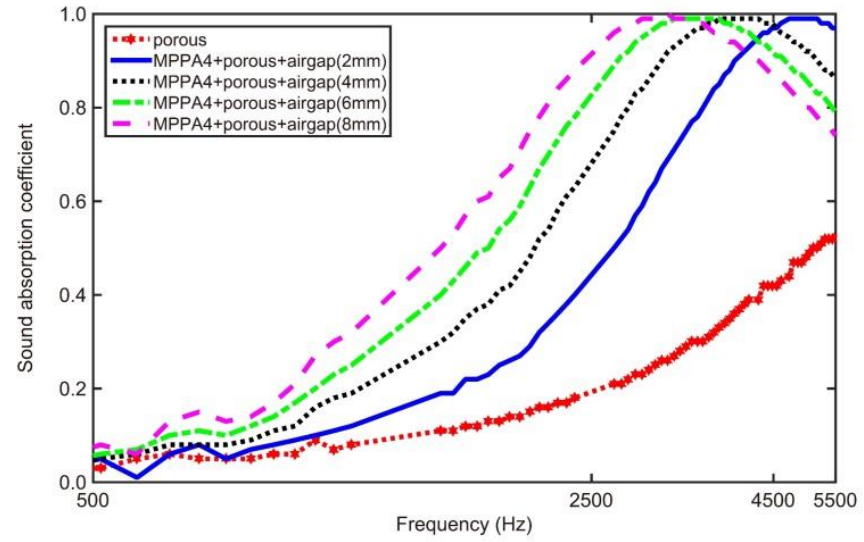

Fig. 8. Measured sound absorption coefficient of multi-layer acoustic absorber consisting of (a) MPPA1, (b) MPPA2, (c) MPPA3 and (d) MPPA4 backed by a porous material and different airgap depths.

\section{Tables}

Table 1

Measured structural parameters for MPPA test specimens in this study.

\begin{tabular}{cccccc}
\hline $\begin{array}{l}\text { Sample } \\
\text { number }\end{array}$ & $\begin{array}{c}\text { Specimen diameter, } \\
\mathrm{D}^{\prime}(\mathrm{mm})\end{array}$ & $\begin{array}{c}\text { Specimen thickness, } \\
\mathrm{t}(\mathrm{mm})\end{array}$ & $\begin{array}{c}\text { Hole spacing, } \\
\mathrm{b}(\mathrm{mm})\end{array}$ & $\begin{array}{c}\text { Hole diameter, } \\
\mathrm{d}(\mathrm{mm})\end{array}$ & $\begin{array}{c}\text { Perforation ratio, } \\
\mathrm{p}(\%)\end{array}$ \\
\hline MPPA1 & 28.96 & 1.02 & 5 & 0.6 & 0.90 \\
MPPA2 & 28.94 & 1.01 & 4 & 0.6 & 1.59 \\
MPPA3 & 28.92 & 1.01 & 3 & 0.6 & 2.63 \\
MPPA4 & 28.95 & 1.00 & 2 & 0.6 & 5.90 \\
\hline
\end{tabular}

